\title{
Awareness on Livelihood Options among Youth of Uttarakhand: A Review
}

\author{
Divyata Joshi $^{1 *}$ and S.K. Kashyap ${ }^{2}$ \\ ${ }^{1}$ Punjab Agricultural University, Ludhiana, Punjab, ${ }^{2}$ Department of Agricultural \\ Communication, G. B. Pant University of Agriculture and Technology, Pantnagar, India
}

*Corresponding author

\section{Keywords}

Youth, Agriculture, Information Gap, Livelihood Options, Awareness

\section{Article Info}

Accepted:

07 February 2019

Available Online:

10 March 2019

\section{A B S T R A C T}

The Himalayan state of Uttarakhand, carved out of Uttar Pradesh in 2000. The state has almost all major climatic zones, making it conducive for commercialization of horticulture, floriculture and agriculture. With this, organic farming and forest based industries has vast potential. People living in this region rich in terms of natural resources happen to be the poorest of the poor and marginalized. They are largely dependent on subsistence agriculture and are struggling to raise their income and quality of life. Mountainous areas still lack employment opportunities making the living of hill people harder. People in hills are moving towards plain areas of the state in search of their livelihood. Studies show that majority of the population which migrates is aged between 15 to 29 years i.e. youth which migrate for search of security, stability and source of income. Most of rural youth comes from agriculture background as majority of the area in Uttarakhand falls under rural area in which 95 percent of the household are primarily dependent on agriculture as a source of livelihood, but the participation of youth in agriculture is only 59 percent. Researches reveal that one the major reason behind migration is information gap persisting among rural youth of hills about the livelihood options already available there. They lack information about new technologies, package and practices, commercialization of crops which is crucial for development of better source of livelihood for them and to raise their standard of living. The youth lack necessary information and knowledge about agriculture production and processing and market. They need to get aware about different ways of engaging in the agriculture sector and making it a potentially lucrative career option.

\section{Introduction}

\section{Concept of youth}

While there is no universally accepted definition of youth, they are defined in number of ways. Different author, scientists and philosophers have given different views upon this. The United Nations general assembly (1985) first defined youth for the international youth year as those persons aged between 15 and 24. Since then United Nations uses this definition without prejudices to the other member countries. This definition is useful for statistical purposes and for development of youth. Youth policy of India draws a line on youth as all individuals aged between 15 to 29 years. Though the definition 
with respect to chronological age fairly serves the statistical purposes for need assessment and overall growth of young people, many other definitions from different perspectives have also been given. According to fact sheet prepared by United Nations Department of Economic and Social Affairs (UNDESA), youth is best understood as a period of transition from dependence of childhood to adulthood's independence. From a psychological point of view, youth identifies to a particular mindset of attitude full of alertness, enthusiasm, vigor and spirit regardless of age. It can also be said that the youth is the phase of person's life when he leaves compulsory education and starts finding source of income. The meaning of the term "youth" also varies in different societies around the world continuously in response to fluctuating political, economic and sociocultural circumstances. African developed countries draw a distinction line on youth as the age from which a person is given equal treatment under the law. Whereas in some developing countries, young person who is not yet married and depends on parents for his socio economic endurance is called as youth. Generally, the term refers to as the age of maturity.

\section{Status of agriculture in Uttarakhand}

Uttarakhand state has unique climatic conditions which is favourable for development of horticulture. The soil condition is good for growing fruits, vegetables and ornamental plants. The climatic conditions allow growing subtropical and temperate fruits and off-season vegetables. A large part of Uttarakhand is hill; and 61.1 percent area is covered under forest and large number of water springs makes it rich in terms of natural resources. But, only 13 percent of the total area is cultivable. So, the size of land holding is less than one hectare. Around 74 percent of land holdings are marginal and 17 percent of operational holdings are small, operating less than two hectare of area. Soil of hill area is mostly shallow and coarse textures. The land is also found undulated.

Subsistence agriculture is the mainstay of the hill economy. Due to this fact, local communities are heavily dependent on land resources. This dependence is compounded by the fact that the availability of land suitable for agricultural is greatly limited. So, the population in hill region has yet to struggle hard for eking out their livelihoods largely from agriculture by putting larger numbers of their household members into the labour force (Mamgain, 2004). One of such hill state is Uttarakhand which is having this as one of the major problem of the state where the rate of migration from rural areas to the urban area is very high. The rate of migration in Uttarakhand is 36.2 percent which is much higher than the national average (30.6\%). Data says that majority of the population migrates to the urban area is 45 percent of the total migrating population; this is reflected by the latest results of Population Census 2011. It shows a very slow growth of population in most of the mountain districts of the state. The two hill districts Almora and PauriGarhwal showed negative population growth and an absolute decline of 17868 persons in the population was seen in these two districts from 2001 to 2011. Historically, these districts had well developed social indicators in comparison to many other districts of the State. The pace of out-migration is so huge that many of the villages are left with a population in single digit.

\section{Opportunities in hill agriculture}

The state is blessed with a rare bio-diversity. It has almost all major climatic zones, making it amenable to a variety of commercial opportunities in horticulture, floriculture and 
agriculture. As stated by Sati (2004) in a study on Horticulture development in Uttarakhand hills, that horticulture including fruits and off season vegetable will play a major role in determining the economic development for the region. Still, horticulture sector in not growing as it is expected to grow. Other Himalayan state Himachal Pradesh has taken full advantage of the natural condition and enhanced the share of primary sector in its gross state domestic product and has become a major exporter of temperate fruits. Uttarakhand is having same climatic conditions but still lagging behind. Sharma (2012) in a study on status of horticulture in Uttarakhand found that to transform the horticulture sector states that it is necessary to steer it from the current subsistence model to a 'hortibusiness-model'. This will be possible only by adoption of a cluster-based approach to create fruit and vegetable belts in each block after due research and studies of location specific farming systems and agro climatic conditions. Consideration of global climatic changes and marketing potentials would also need due consideration when planning for the future development of horticulture sector.

There is wide scope for medicinal and aromatic plants as a means of livelihood for Himalayan region as 175 rare species of aromatic \& medicinal plants are found in this region. Medicinal and aromatic plants are high value crops with high demand in pharmaceutical industry. Medicinal plants are constituents of medicines and aromatic plants are used in cosmetics, soaps and perfumes, so they serve as a good source of income generation. Phondani et al., (2016) in a study on promoting medicinal plants cultivation as a tool for biodiversity conservation and livelihood enhancement in Indian Himalaya found that medicinal and aromatic plants can serve as a good source of livelihood and income generation to poor rural communities.
As medicinal plants are high value crops and have high demand for the pharmaceutical industry.

Forests play an important role in the economy of the state as majority ( $>60 \%)$ of the area is covered under forest. Timber and fuel form the major produce group, while bamboo, drugs, grasses, gum and resins etc., the minor produce group. One specific species of bamboo is also found in Himalayas which can be commercialized and created as a source of livelihood. Arya (2014) in a study on dwarf bamboo (ringal): a traditional livelihood option for Garhwal Himalaya found that people retain ample knowledge about the traditional art of ringal weaving work. About 47.65 percent families earned some monies from this art and craft based work. This generated income plays an important role in sustaining and strengthening their livelihood and socio-economic status. Forests are also the major source of raw materials for industries, buildings, railways and other tertiary sectors. A number of small scale industries heavy and medium industries are also there which are providing employment to a large number of people. Most of the industries are forest-based.

State has a vast tourism potential in adventure, leisure, and eco-tourism. There are a total of 54,047 handicraft units in the state which can enhance the opportunities for taking entrepreneurial ventures. Sekhar (2007) in his study on Viable Entrepreneurial Trade for Women in Agriculture in Utttaranchal highlighted that more than 50 percent of household income was generated through poultry farming, papad making, and petty business. Other main economic activities are dairy farming, mushroom cultivation, bee-keeping and quilt-making. Income higher than poverty line has been generated by these business activities. People living in this region rich in terms of natural 
resources happen to be the poorest of the poor and marginalized. They are primarily dependent on subsistence agriculture and forest resources and are struggling for raising their income and quality of life.

Vast opportunities are there in hills but the pattern of growth and employment has been disappointing as it appears to be largely distress driven. Agriculture still remains the dominant sector of employment. According to Mamgain (2007) while comparing with allIndia, the share of agriculture in employment is relatively higher by 6.6 percentage points in Uttarakhand in 2004-05. But now it is failing due to lack of diversification in agriculture. Agriculture now perceived as a non profitable and insecure sector with the sustainability issues. And youth are moving towards the non agriculture sector over the years and exploring entrepreneurial opportunities. Millions of educated unemployed youth across the hill state, mostly from the farming families are waiting for the jobs. Even though many of these educated unemployed youth have acquired traditional knowledge of farming from their families, but they no longer find it remunerative to get engaged in it. As stated by Maikhuri et al., 2011, now, rural migration is seen as a survival or a subsistence strategy for rural masses. Frustrated youth are now migrating in large number to the urban and industrial region in the plain areas in search of employment.

\section{Status of youth related to information regarding agriculture}

Till date what has been done to improve the livelihood status and standard of living of people in hills of Uttarakhand, it has been seen that there is an information gap which is persisting among people of hills about the options that are already available there. Though abundance of options is there but still migration has not been controlled because there is a lack of proper information in youth about these livelihood options as one of examples Roy and Bhagat (2012) in a study on level of knowledge and extent of adoption of farmers on recommended tuberose production practices found that majority (70\%) of the respondents belonged to medium knowledge level category followed by high knowledge level (20\%) about tuberose production technology. The results of this study were in line with other similar studies where it was found that the awareness or knowledge level of the farmers was medium about the new commercial crop practices followed by low level of awareness.

Across the Himalayan region, the farmers in the rural areas face problems in accessing market information, information about input facilities and government policies related to different livelihoods. Gangwar (2014) in a study on attitude of rural youth towards agriculture as a means of livelihood found lack of awareness about inputs and government policy as one of the major constraints faced by youth in choice of agriculture as a career. One reason behind this lack of awareness as told by Azeez and Augustine (2013) in a study on role of youth resource centre in empowering rural youth is that rural youth are deprived in the grounds of lack of accessibility in education, employment and participation as compared to urban youth. And also, the problems, risk factors, opportunities and accessibility is having high level of variation in different sub groups like women youth, tribal youth, so high degree of attention is needed as majority of youth belong to the rural area.

All planned changes require suitable information to change the attitude, enhance knowledge and build suitable skill on the part of the beneficiaries to undertake livelihood activities by residing in the hills itself. However, sharing right information at the 
right time and in the right perspective is not an easy task. There are several factors which are working as constraints in the flow of information among rural people of hills, leading to lack of awareness of poor masses that are vulnerable and prone to migration. One major barrier in information flow about livelihood options is limited number of extension staff and their irregular visit. Surindar and Vasanthakumar (2001) in a study on a comparative analysis of information sources for agricultural and horticultural development revealed that majority $(>85 \%)$ of farmers practicing agriculture and horticulture quoted irregular visit of the extension workers/ officials as the problem in receiving information related to agriculture and horticulture cultivation. The 94 percent of the respondents also suggested regularization of the visits of extension personnel and they should act as a complementary source of information for farmers. Other related constraints as suggested by Omar et al., (2012) in a study on the impact of major constraints on agricultural extension, were lack of training program, lack of motivation and weak linkages between researchers.

The people in hill region live in the farthest places so there is a problem of accessibility to information sources and the time of information given is also not appropriate. Talitemsu (2003) in a study on information needs and information seeking behaviour of educated unemployed youth in Nagaland also reported that the educated unemployed youth face various barriers while seeking information. The three major barrier identified in the study was personal barrier which includes inability to access of information resources, lack of concentrated information, lack of clarity of information need and purpose, non availability of resources in the centre and time factor.
Also there are some socio-cultural factors which inhibit the smooth flow of information to the rural areas e.g. In some of the places rural girls are not allowed to talk to an outsider, such types of barriers create hindrance in information flow. To go for an entrepreneurial venture is underestimated in some of the areas. Also reported by Saha and Bahal (2012) in a study on constraints impeding livelihood diversification of farmers in West Bengal that there are many problems faced by farmers like negative perception of the community, lack of marketing facility of improved technology and skills, inadequate or no experience of new occupation, shyness in doing socially underestimate work and lack of business startup budget.

Both the sides i.e. farmers and extension agencies create some kind of barriers due to which there is a gap in information between them. Sometimes the information given by the extension workers is not utilized by the farmers properly. One reason is they are less cosmopolite in nature and have less extension agency contact; less mass media exposure and they are less information seeking. They do not apply new technologies given by the agencies and rely only on subsistence farming as also reported by Mandal and De (2013) in a study on factors affecting sources of information utilization showed that majority of the respondents $(86 \%)$ had medium level of information source utilization. And socioeconomic status, interpersonal interaction and value orientation are the variables which affect the sources of information utilization of farmers.

The ratio of number of farmers per extension personnel is very high i.e.1000:1 due the limited and trained extension staff. They sometimes are unable to provide need based timely information to the farmers residing in the remote areas. The information given is not satisfactory because of which they lack 
credibility form rural people. Mohanty et al., (2013) in a study on constraints analysis in adoption of vegetable production technologies for livelihood perspective of tribal farmers in North Sikkim found low responsiveness and lack of effective supervision and monitoring by extension workers and low credibility of extension workers as one of the major constraint resulting vegetable cultivation as a non- profitable enterprise.

In past researches it has been found that mass media, especially radio and television, is the best communication source for creating awareness and interest among the audience regarding new idea and message. In the agriculturally non-progressive villages, the exposure of mass media of communication is almost negligible. This lack of exposure to the communication channels lead to the gap in information about the new technologies, practices, market availability etc in the rural youth. Appropriate mass media can play a crucial role in creating environment for development as well as patches the communication gaps between government and different stakeholders which can become an alternative to minimize the communication gap, community radio is a good example which has been serving as a source of information in the country at grass root level since last one decade but still the communication gap is prevailing in the rural areas.

On the other hand, interpersonal sources such as, extension personnel, friends, social leaders and others are the most effective sources in transferring a new technology in general and adoption of the new technology in particular. The use of these information sources depend person to person, their condition and location, the needs, interest, reliability, availability and accessibility. If both, mass media and interpersonal sources will be used in effective manner the gap can be reduced to a greater extent.
In conclusion, in hilly areas abundance of livelihood options are available so proper data and information about need based livelihood options on the basis of agro-ecological zones and socio-economic profile of the people of that area can be properly documented to increase the level of awareness among them which in-turn will reduce the rate of migration towards the plain area.

A complete communication strategy by using different types of media like mass media, group contact and interpersonal channels and some new approaches like media mix, participatory and community media according to agro-ecological situation in hilly areas to smoothen the flow of information among rural people about the available and probable livelihood options should be identified and standardize which will lead to better communication network and better information at grass root level and the persisting gap between the researcher and farmer will be altered.

Agriculture universities, extension agencies and research institutions have worked consistently to generate appropriate technologies to promote livelihood options and income. These technologies will generate a change only when these are adopted by the farmers and youth in fields. It is necessary to analyze the extent up to which these technologies have been adopted by the farmers this kind of a study can cater to the problem of migration from hills.

There are several factors which are working as constraints in the flow of information leading to low level of awareness of poor masses that are vulnerable and prone to migration. Adequate study on the reasons behind low level of awareness and linking data related to the level of awareness and reasons behind it should be studied which will help in reducing the loop-holes persisting between different stakeholders. 


\section{References}

Arya, D. 2014. Dwarf bamboo (ringal): a traditional livelihood option for schedule caste families of Garhwal Himalaya. International Journal of Advanced Research in Engineering and Applied Sciences, 3(7)

Azeez, A. and Augustine, S. 2013. Role of youth resource centre in empowering rural youth: A case study. Asian Journal of Research in Social Sciences and Humanities, 3(10):92-101

Bennell, P. 2007. Promoting livelihood opportunities for rural youth of South East Asia. Conference proceedings, Knowledge and Skills for Development, February.

Gangwar, R. 2013. Attitude of rural youth towards agriculture as a means of livelihood: A study in the Tarai region of Uttarakhand. Unpublished Thesis M. Sc., Department of Agricultural Communication, GBPUAT, Pantnagar.

Mamgain, R. P. 2004. Employment, Migration and Livelihoods in the Hill Economy of Uttaranchal. Ph.D. Thesis, Centre for the Study of Regional Development, Jawaharlal Nehru University, New Delhi.

Mandal, B. K. and De, D. 2013. Factors affecting sources of information utilization. Indian journal of extension education, 49(1,2): 93-95

Mohanty, A.K., Lepch, B. and Kumar, A. 2013. Constraints analysis in adoption of vegetable production technologies for livelihood perspective of tribal farmers in North Sikkim. Indian Research Journal Extension Education, 13(2) may 2013

Mamgain, R.P. 2007. Growth poverty and employment in Uttarakhand. Institute for Human Development. New Delhi. Working Paper no. 39: 8-9

Maikhuri R.K., Rawat L.S., Negi Vikram S.,
Agarwal Sunil K., Rao K.S., Saxena K.G. 2011. Managing natural resources through simple and appropriate technological intervention for mountain development, Current Science, 100(7): 992-997.

Omar, J., Bakar, A., Jais, H. M. and Shalloof, F. 2012. The impact of major constraints on agricultural extension in Eastern Lebia. Journal of Agricultural Technology, 8 (4): 1171-1183

Phondani, P. C., Bhatt, I. D., Negi, V. S., Kothyari, B. P., Bhatt, A. and Maikhuri, R.K. 2016. Promoting medicinal plants cultivation as a tool for biodiversity conservation and livelihood enhancement in Indian Himalaya. Journal of Asia-Pacific Biodiversity, 9:39-46

Pratap, T. 2011. Sustainability factors of hill agriculture and opportunities. Journal of Hill Agriculture, 2(1): 1-13

Roy, S. and Bhagat, R. 2012. Level of knowledge and extent of adoption of farmers on recommended tuberose production practices. Indian Journal of Extension Education, 48 (1\&2): 78-80

Saha, B. and Bahal, R. 2012. Constraints impeding livelihood diversification of farmers in West Bengal. Indian Research Journal of Extension Education, 12(2) may 2012

Sati, V.P. 2004. Horticulture development in hills: a case for the Alaknanda basin. New Delhi. Mittal publication. P. 123

Sekhar, C.S.C. 2007. Viable Entrepreneurial Trade for Women in Agriculture in Uttaranchal. Working Report, Agriculture Economics Research Centre, University of Delhi.

Sharma. 2007. The changing agriculture demography of India: Evidence from a rural youth perception survey. International Journal of Rural Management, 3(27):125-130

Sharma, A. K. 2012. Status of horticulture in 
Uttarakhand. Journal of Hill Agriculture 3(2): 69 -76, July December.

Surindar, V. and Vasanthakumar, J. 2001. A comparative analysis of information sources for agricultural and horticultural development. Journal of Communication Studies, 19(2): 15-20
Talitemsu. 2003. Information needs and information seeking behaviour of educated unemployed youth in Nagaland. Unpublished Thesis, Department of library and information sciences, North eastern hill university, Nagaland.

\section{How to cite this article:}

Divyata Joshi and Kashyap, S.K. 2019. Awareness on Livelihood Options among Youth of Uttarakhand: A Review. Int.J.Curr.Microbiol.App.Sci. 8(03): 648-655.

doi: https://doi.org/10.20546/ijcmas.2019.803.080 